Ilham H. Al-Abdulla BDS, MSc. (Asst. Lect.)

\section{The Effect of Some Disinfectants on Some Mechanical Properties of Nylon (Valplast) Denture Base Material}

Prosthodontic Department

College of Dentistry, University of Kerbala

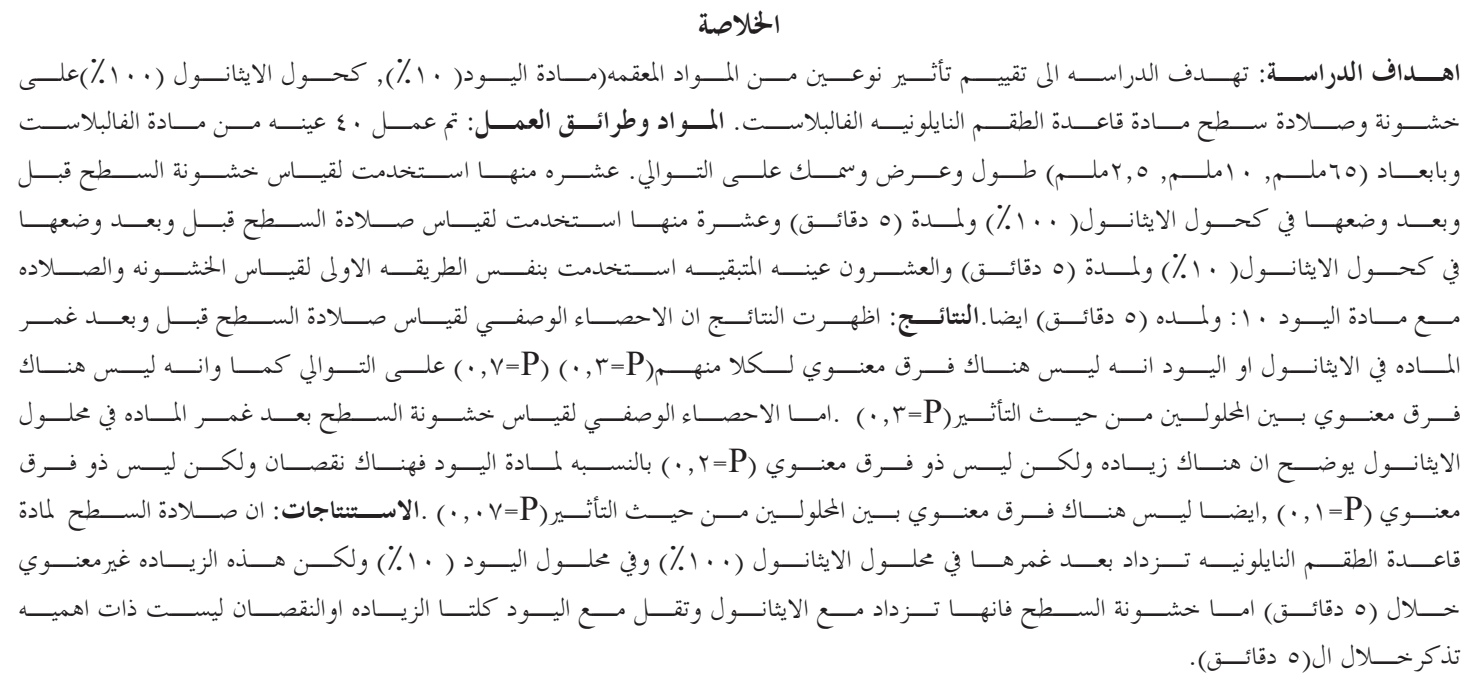

ABSTRACT

Aims: To evaluate the effect of two disinfecting solutions (povidone iodine 10\%, ethanol alcohol 100\%) on the surface roughness and surface hardness of nylon denture base material. Materials and Method: 40 sample of valplast material were constructed with dimensions of $(65 \mathrm{~mm}, 10 \mathrm{~mm}, 2.5 \mathrm{~mm})$ length, width and thickness respectively. (10) samples were used to measure the surface roughness before and after soaking in (ethanol material 100\%) for $5 \mathrm{~min}$., (10) samples were used to measure the surface hardness before and after soaking in (ethanol alcohol 100\%) for $5 \mathrm{~min}$., other 20 samples have been used in the same way as the 1st 20 but with iodine disinfectant. Results: Descriptive statistics for indentation hardness of valplast in ethanol and iodine indicate there is no significant difference for each one $(\mathrm{P}=0.3, \mathrm{P}=0.7$ respectively).T-test indicate there is no significant difference between them $(\mathrm{P}=0.3)$. Descriptive statistics for surface roughness in ethanol indicate there is an increase but it is not significant $(\mathrm{P}=0.2)$, while for iodine there is a decrease also it is not significant $(\mathrm{P}=0.1)$.T-test indicate no significant difference between them $(\mathrm{P}=0.07)$. Conclusion: Hardness of nylon denture base material increased by immersing in each of the ethanol and iodine but their increase is not significant (within $5 \mathrm{~min}$.). Surface Roughness of nylon denture base material increases by immersing in ethanol alcohol while it decreases by immersing in iodine, this increase or decrease is not significant (within $5 \mathrm{~min}$.).

Key words: Nylon denture base, polyamide sterilizations, surface roughness, surface hardness.

Al-Abdulla IH, The Effect of Some Disinfectants on Some Mechanical Properties of Nylon (Valplast) Denture Base Material. Al-Rafidain Dent J. 2015; 15(1): 374-380.

Received: $15 / 5 / 2013 \quad$ Sent to Referees: $30 / 5 / 2013$

Accepted for Publication: 22/7/2013

\section{INTRODUCTION}

Favorable denture base material is needed for fabricating long lasting and biologically acceptable dentures. ${ }^{(1)}$ Acrylic polymethylmethacrylate (PMMA) is one of the most widely used denture base material with numerous advantages ${ }^{(2)}$, but PMMA has poor mechanical properties like fracture due to unsatisfactory transverse strength, impact strength, or fatigue resistance ${ }^{(3)}$, allergic reactions to PMMA are also reported ${ }^{(4)}$.

Studies have been done to improve the mechanical properties of (PMMA) and in recent years nylon polymer has gained attractive attention as a denture base material because of many advantages: favorable esthetic outcome(non metal clasp), toxological safety to patients allergic to metals and resin monomer, higher elasticity than conventional heat polymerizing resins and sufficient strength for use as denture base material. ${ }^{(5)}$

Thermoplastic material in spite of all these benefits, it has some difficulty to adjust and polish ${ }^{(6)}$. 
Dental prosthesis passes in many stages within the laboratory such as flasking, finishing and polishing. It will come in contact with many instruments it will be contaminated .So disinfection of dental prosthesis is mandatory before delivery to the patient in order to reduce the risk of transfer of infection, elimination of bacterial, viral and fungal reservoirs and establishing discipline for asepsis. Iodophors, chlorine solutions, gluteraldehydes, or phenols are all acceptable for this $\operatorname{step}^{(7)}$.

In this study we used two types of disinfectants (Povidone iodine 10\%, ethanol alcohol $100 \%$ ) to disinfect specimens were made of nylon denture base material and we measured their effect on the surface hardness and surface roughness of the specimens.

\section{Materials and Methods}

Valplast plastic bag (FDA, MSDs,ISO, USA) as in the Figure (1), Pumice, Rouge, Ethanol alcohol (100\%), Povidone iodine $(10 \%)$, Digital surface roughness tester (maximum reading 3 micron), Shore $\mathrm{D}$ hardness tester, Special heating flasks for plastic injection as in Figure (2), Finishing burs (tungsten carbide, stone, green finishing cone).

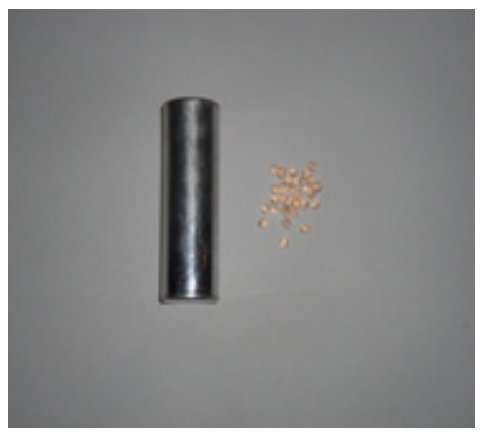

Figure (1): Valplast plastic bag

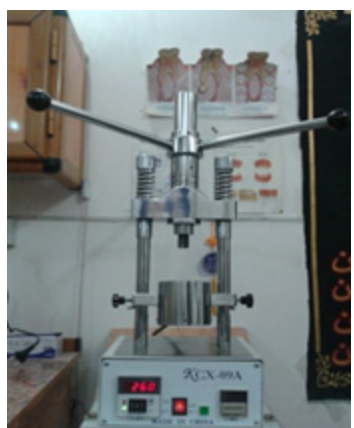

Figure (2): Injection machine

\section{Specimens Grouping :}

Forty samples of valplast base plate material were prepared with dimensions $(65 \mathrm{~mm}, 10 \mathrm{~mm}, 2.5 \mathrm{~mm})$ length, width and thickness respectively ${ }^{(8)}$. They were divided as the following:

1. 20 sample were soaked in ethanol alcohol 100\% (10 samples for the indentation hardness test \& 10 samples for the surface roughness test).

2. 20 sample were soaked in povidone iodine $10 \%$ (10 samples for the indentation hardness test \& 10 samples for the surface roughness test).

Preparation of the nylon (valplast) specimens by the same conventional way for nylon injection as in Figure (3) and (4). 


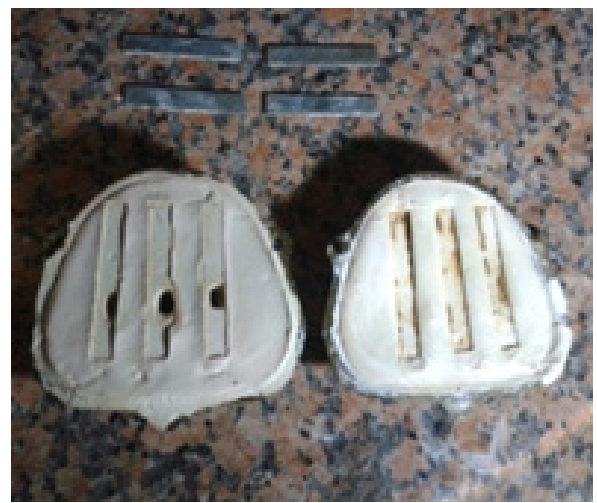

Figure (3): Valplast plastic bag

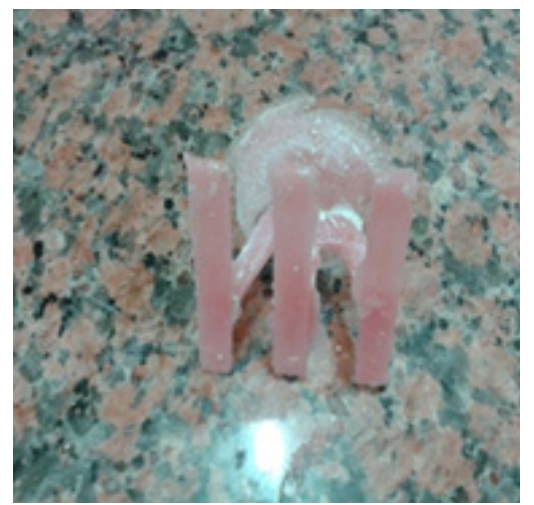

Figure (4): Injection machine

\section{Finishing and polishing :}

The nylon specimens were finished and polished according to the manufacturers recommendation. First by the use of tungsten carbide bur (5000 rpm)at low pressure to prevent melting of the material. Then stone bur, then green rubber cone was used (5000rpm) to complete the finishing process and produce smooth surface. The final glossy surface were obtained by polishing with pumice , then with rouge on wool brush of dental lathe (10 times for each sample).As in the Figure (5).

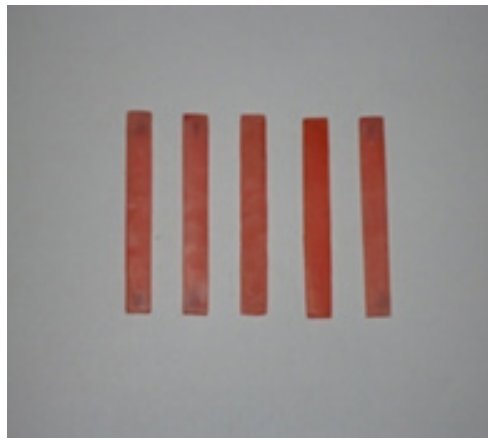

Figure (5): Valplast samples after finishing

\section{Mechanical tests :}

Identation hardness (shore D test) test, and Surface roughness. The specimens were divided into four groups. The indentation hardness test were measured by the use of shore D hardness tester for the First two groups. The first group were soaked in an ethanol alcohol $100 \%$ for ( $5 \mathrm{~min}$.) in a closed container, While second group were soaked in povidone iodine $10 \%$ for $(5 \mathrm{~min}$.) in a closed container. Then they were washed with tab water and dried to be ready for indentation hardness test measurement after soaking by the same device as in the Figure (6). 


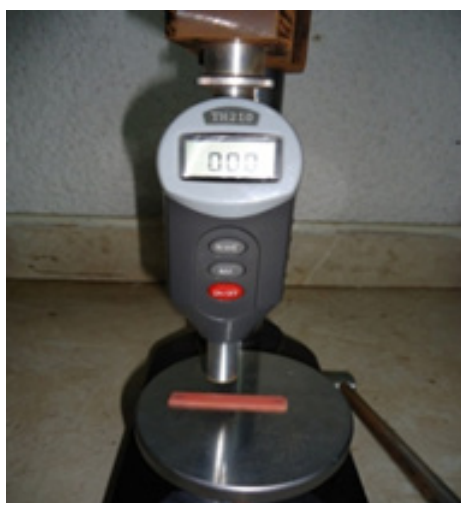

Figure (6): Shore D hardness test

Three readings were taken for each sample and the mean represent the hardness value for each sample. ${ }^{(7)}$

The surface roughness test were measured by the use of digital surface roughness tester (profilometer), where the diamond stylus surface analyzer move $(2 \mathrm{~mm})$ across the surface of nylon specimen. This test were measured for the third and forth group .Then the third group were soaked in an ethanol alcohol $100 \%$ for $(5 \mathrm{~min}$.) in a closed container, While forth group were soaked in povidone iodine $10 \%$ for $(5 \mathrm{~min}$.) in a closed container. Then they were washed with tab water and dried to be ready for surface roughness test measurement after soaking by the same device. ${ }^{(9)}$ Two readings were recorded for each specimen and the mean value was the average of two readings for each specimen. The results were expressed in micrometer ${ }^{(9)}$ as in the Figure (7).

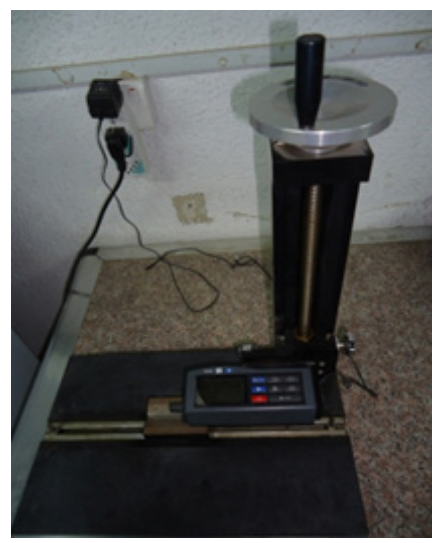

Figure (7): Digital surface roughness tester

\section{Results}

\section{Indentation hardness:}

The mean and standard deviation of indentation hardness values for ethanol and iodine indicate that there is an increase in the hardness of nylon denture base material after soaking in each of the iodine and ethanol as in Table (1).

Table (1) :Descriptive statistics indentation hardness values of pre and post-soaking in each of the ethanol alcohol $100 \%$ and povidone iodine $10 \%$

\begin{tabular}{cccc}
\hline Hardness test & No. & Mean & SD \\
\hline Presoaking in ethanol & 10 & 69.840 & 2.860 \\
Postsoaking in ethanol & 10 & 70.840 & 1.890 \\
Presoaking in iodine & 10 & 70.090 & 1.010 \\
Postsoaking in iodine & 10 & 70.216 & 0.933 \\
\hline
\end{tabular}


This increase is non significant (with ethanol $\mathrm{P}$-value $=0.3$, with iodine $\mathrm{P}$ - value $=0.7$ ) as in Table (2), Mean is higher with ethanol than with iodine but there is no significant difference between these two data $(\mathrm{P}$ value $=0.3)$ as in Table (3).

Table (2) : T-test of indentation hardness test between pre and post-soaking in each of the ethanol alcohol $100 \%$ and povidone iodine $10 \%$

\begin{tabular}{ccc}
\hline Hardness test & No. & Mean \\
\hline Presoaking in ethanol & 69.840 & $0.373^{* *}$ \\
Postsoaking in ethanol & 70.840 & \\
Presoaking in iodine & 70.090 & $0.770^{* *}$ \\
Postsoaking in iodine & 70.216 & \\
\hline
\end{tabular}

$* \mathrm{P} \leq 0.05$ significant $\quad * * \mathrm{P}<0.05$ non significant

Table (3) : T-test (significance) for the indentation hardness between postsoaking in the ethanol alcohol $100 \%$ and povidone iodine $10 \%$

\begin{tabular}{ccc}
\hline Hardness test & No. & Mean \\
\hline Postsoaking in ethanol & 70.840 & $0.367^{* *}$ \\
Postsoaking in iodine & 70.216 & \\
\hline
\end{tabular}

\section{Surface Roughness:}

The mean and standard deviation of surface roughness values for ethanol and iodine indicated that there is an increase in surface roughness with ethanol but it is not

significant difference $(\mathrm{P}-\mathrm{value}=0.2)$. While there is a decrease in surface roughness with iodine also it is non significant difference $(\mathrm{P}$ value $=0.1)$ as in Table (4 and 5).

Table (4): Descriptive statistics of surface roughness for pre and postsoaking in each of the ethanol alcohol $100 \%$ and povidone iodine $10 \%$

\begin{tabular}{cccc}
\hline Roughness test & No. & Mean & SD \\
\hline Presoaking in ethanol & 10 & 0.964 & 0.174 \\
Postsoaking in ethanol & 10 & 1.134 & 0.370 \\
Presoaking in iodine & 10 & 1.006 & 0.207 \\
Postsoaking in iodine & 10 & 0.881 & 0.162 \\
\hline
\end{tabular}

Table (5): T-test ( significance) of surface roughness between pre and postsoaking in each of the ethanol alcohol 100\% and povidone iodine $10 \%$

\begin{tabular}{ccc}
\hline Roughness test & Mean & P-Value \\
\hline Presoaking in ethanol & 0.964 & $0.215^{* *}$ \\
Postsoaking in ethanol & 1.134 & \\
Presoaking in iodine & 1.006 & $0.153^{* *}$ \\
Postsoaking in iodine & 0.881 & \\
\hline
\end{tabular}

$* \mathrm{P} \leq 0.05$ significant $\quad * * \mathrm{P}<0.05$ non significant

T-test of surface roughness between ethanol and iodine post-soaking indicated that there is no significant difference $(\mathrm{P}$ value $=0.07)$ as in Table (6).

Table (6) : T-test ( significance) of the surface roughness between postsoaking in the ethanol alcohol $100 \%$ and povidone iodine $10 \%$ ethanol alcohol $100 \%$ and povidone iodine $10 \%$

\begin{tabular}{ccc}
\hline Roughness test & Mean & P-Value \\
\hline Postsoaking in ethanol & 1.134 & $0.072^{* *}$ \\
Postsoaking in iodine & 0.881 & \\
\hline
\end{tabular}




\section{Discussion}

Nylon is acrystalline polymer, this crystallinity account for the nylon resistance to solubility in solvents, high heat resistance and high strength coupled with ductility. ${ }^{(10)}$

Most popular chemicals used for denture disinfection are house hold bleach, chlohexidine and gluteraldehyde. They act by destroying microorganisms but not their spores . ${ }^{(11)}$ It has been reported that ethanol is a propylalcohol, chloroform, formalin and acetic acid may be used for occasional disinfection of dentures and to avoid contamination. ${ }^{(12)}$

Tieng (2008) investigated the effect of oxygenating denture cleanser on surface roughness and hardness of nylon denture base material and on conventional heat cured acrylic. The study indicated that the surface roughness and hardness of nylon was significantly decreased while no significant effect on the surface roughness and hardness of conventional heat cured acrylic. ${ }^{(13)}$

Nylon are relatively insensitive to non polar solvents ,however, because of the presence of the polar groups, nylons can be affected by polar solvents, particularly water. $^{(14)}$

Nylon exhibits high physical strength, heat resistance and chemical resistance. ${ }^{(15)}$

Hardness: Is a term used to describe the resistance of the material to indentation and also it is a measure of the resistance to wear or scratching. ${ }^{(16)}$ Many methods for evaluating this property have been described including Brinell, Knoop, Viker, Rockwell and Shore. ${ }^{(17)}$

In this study Shore D hardness test was used which was found to be suitable for nylon denture base material. Statistical analysis of the results showed that there is no significant difference on hardness of nylon by ethanol also by iodine and no significant effect between ethanol and iodine.

This result occurred due to that nylon polymerized by condensation polymerization leading to the formation of aliphatic polymer without cross linking polymer chain. ${ }^{(18)}$

Other explanation is that, nylon is more packed and less intermolecular spaces polymer, the polymer chains are not contain side groups so less water diffusion. This agreed with Yota $(2010)^{(10)}$ who stated that nylon is a highly chemical resistant material due to its high degree of crystalinity too less water and alcohol absorption .So this may explain the non significant effect of ethanol and iodine on nylon hardness.
Increase the surface roughness has a detrimental effect on the esthetic of the denture, the smooth shiny surface of the denture base help to resist the build up of stain, debris and plaque. Deterioration of the polished surface lead to stain build up, plaque accumulation, loss of surface detail and made the ingress of the bacteria that penetrate the denture base much easier. ${ }^{(19,20)}$

The profilometer appears to be excellent device for studying the surface roughness of restorative material. It gives a quantitative measurement with low percentage of error that can be evaluated and compared statistically. ${ }^{(21,22)}$

The result of the surface roughness of nylon by ethanol and iodine showed that there is no significant difference in surface roughness of nylon .This mean absence of the effect of disinfectant on nylon surface geometry. There is no other study in the literature for direct comparison.

\section{Conclusion}

1.Hardness of nylon denture base material increased by immersing in each of the ethanol and iodine but their increase is not significant (within 5 min.).

2.Surface Roughness of nylon denture base material increases by immersing in ethanol alcohol while it decreases by immersing in iodine, this increase or decrease is not significant (within 5 min.).

\section{References}

3. Khindri SK, Sanjeer M, Urvashi S. Evolution of denture base materials .J ind Prosthodont Soci. , 2009;9(2):64-69

4. Anusavice KJ. Philip's Science of dentalmaterials.10th ed.Philadelphia 2003: Saunders 89-90.

5. Yazadin N and Mahood M. Carbonfiber acrylic resin composite :an investigation of transverse strength. Journal of Prosthetic Dentistry 1989 44(4):542.

6. Mabraden JK. Some aspects of the chemistry and physics of dental resins. Adv Dent Res ; 1988,2(1):93-97.

7. Yuki KF, Satoru HO, Naho HN. Bonding strength of autopolymerizing resin to nylon denture base polymer. J Dent Mat.2009; 28(4):409-418.

8. Ulusoy M; Ulusoy N; Aydin A.K. An evaluationof polishing techniques on surface roughness of acrylic resins. Journal of Prosthetic Dentistry 1986;56(1): 107-12.

9. Hammed M.S.The effect of different denture cleanser solusions on some 
mechanical \&physical properties of nylon \& heat cured acrylic denture base material.M.Sc.thesis. College of dentistry. University of Baghdad 2011 ,P:56

10. Ahmad N.Evaluation of thermal conductivity of alumina reinforced heat cure acrylic resin and some other properties .M.Sc.thesis College of Dentistry ,University of Baghdad 2010.

11. Jassim M.M. Evaluation of Candida albicans attachment to flexible denture material base (valplast) and heat cure acrylic resin using different finishing and polishing techniques.M.Sc. thesis.College of Dentistry .University of Baghdad 2011, P:59.

12. Yota T. characterstic of denture thermoplastic resins for non-metal clasp dentures. Dent Mat J. ,2010, 29(4): 353-361

13. Jagger DC, Harrison A: Denture cleaning. The best approach. Br Dent J 1995, 178: 413-417.

14. Budtz-Jorgensen E. Material and method for cleaning denture Journal of Prosthetic Dentistry 1979. 42(6):619.

15. Tieng C. Effect of denture cleanser on the surface roughness and hardness of denture base material. M.Sc.thesis .Mahidol University 2008.

16. Toloken S., Recycling Program in the works for PCV, Plastics News, Aug.31, 1998, P:5.

17. Kutsch VK.; Whitehouse J.; Schermerhorn
K.;Bowers R. The evolusion and advancement of dental thermoplastics. Dental town, Feb 2003; 2:52-56.

18. John M Power and Ronald L Sakaguchi. CRAIG'S Restorative Dental materials. 12th edition .St Louis. Mosby 2006. P: $53,67,261$.

19. Craig RG and Powers JM. Restorative dental material 11th edition 2002. St Louis. Mosby CO. P:65, 118, 215, 243.

20. Antonio MC: Structure development during polymer processing. 2nd edition 2000 , Cambridge Comp., London, UK., $\mathrm{P}: 123$.

21. Webb BC, Willcox MD, Thomas CJ. Candida associated denture stomatitis. Aust Dent J 1998a, 43: 244.

22. Harrison Z, Johnson A, Douglas CW. An in vitro study into the effect of limited range of a denture cleanser on surface roughness and removal of Candida albicans from conventional heat cured acrylic resin denture base material. J Oral Rehabil. 2004, $31: 460-462$.

23. Matsumura $\mathrm{H}$, and Leinfelder KF. Three body wear of four type of light activated composite resin veneering materials.1994. Quintessence Int, 25: 425-430.

24. Al-Dabag RKJ. The effect of denture cleansers on the surface roughness of denture base material. Master Thesis .College of dentistry, University of Baghdad 1996 